\title{
Growing a sustainable local grain economy in Arizona: A multidimensional analytical case study of an alternative food network
}

\author{
Nigel Forrest ${ }^{\mathrm{a} *}$ and Arnim Wiek ${ }^{\mathrm{b}}$ \\ Arizona State University
}

Submitted August 4, 2020 / Revised November 23 and December 17, 2020 / Accepted December 17, 2020 /

Published online April 8, 2021

Citation: Forrest, N., \& Wiek, A. (2021). Growing a sustainable local grain economy in Arizona: A

multidimensional analytical case study of an alternative food network. Journal of Agriculture, Food Systems,

and Community Development, 10(2), 507-528. https://doi.org/10.5304/jafscd.2021.102.031

Copyright (C) 2021 by the Authors. Published by the Lyson Center for Civic Agriculture and Food Systems. Open access under CC-BY license.

\begin{abstract}
Local grain economies are being developed in North America and Europe as alternatives to the global grain economy and its negative externalities. Little is known, however, about their size, structure, and sustainability, in particular as they evolve. This study offers such insights from a case study of the local grain economy in Arizona. The study uses an analytical framework that combines quantitative and qualitative data and a number of analytical methods to construct a multidimensional profile of the local grain economy. The findings indicate steady growth of the local grain economy in Arizona - in production quantities, range of businesses, diversity of products, and local economy benefits over a number of developmental stages. The findings also suggest that challenges of consolidation, transparency, and other growth

a* Corresponding author: Nigel Forrest, Postdoctoral Research Associate, School of Sustainability, Sustainable Food Economy Lab, Arizona State University; P.O. Box 875502; Tempe, AZ 85287-5502 USA; nforrest@asu.edu

b Arnim Wiek, Professor, School of Sustainability, Sustainable Food Economy Lab, Arizona State University; P.O. Box 875502; Tempe, AZ 85287-5502 USA; arnim.wiek@asu.edu
\end{abstract}

issues might undermine its sustainability. The insights can inform the further development of the local grain economy in Arizona and other regions. The study also provides a framework that, through comparative research, allows for creating generalized knowledge about local grain economies and alternative food networks.

\section{Keywords}

Local Grain Network, Sustainable Local Economy, Short Supply Chain, Artisan Mills and Bakeries, Craft Malt and Beer, Relocalization, Alternative Food Network, Analytical Framework

\section{Funding Disclosure}

The authors acknowledge funding for this research through the grant "TRANSFORM: Accelerating Sustainability Entrepreneurship Experiments at the Local Scale," funded by the Social Sciences and Humanities Research Council (SSHRC) of Canada (Partnership Grant Program), as well as the grant "Globally and Locally-Sustainable Food-WaterEnergy Innovation in Urban Living Labs (GLOCULL)," funded by the National Science Foundation (Award Number 1832196) in coordination with the Belmont Forum and the Joint Programming Initiative Urban Europe (Program "Sustainable Urbanisation Global Initiative-Food-WaterEnergy Nexus, SUGI-FWE Nexus). 


\section{Introduction}

Many regions of North America and Europe have been re-localizing their grain economy over the last decade (Carlisle, 2019; Halloran, 2015; Smith \& Barling, 2014). Driven by the same social, cultural, ecological, and economic concerns as alternative food networks (Renting, Marsden, \& Banks, 2003), clusters of small grain growers, processors, and producers offer alternatives to the commodified and centralized grain industry (Carlisle, 2019; Halloran, 2015; Hergesheimer \& Wittman, 2012; Hills, Goldberger, \& Jones, 2013a; Jones \& Harvey, 2017; Robinson, 2020; Steavenson, 2019). As the need for sustainable alternatives increases, so does the need to better understand them and how they might be supported toward achieving their goals. With this in mind, we investigate the local grain economy in Arizona through an analysis of its structure and development and a preliminary appraisal of its sustainability.

Emerging in the 1990s and gaining momentum since the late 2000s, local grain economies have grown in size and number, often as grassroots initiatives driven by passionate individuals (Halloran, 2015; Nabhan, 2018; Sen, 2008; Thomas, 2013). Examples exist in New York (Halloran, 2015), New England (Halloran, 2015; Jones \& Harvey, 2017), Western Washington (Hills et al., 2013a), British Columbia (Hergesheimer \& Wittman, 2012), England (Steavenson, 2019), Scotland (Robinson, 2020), Lower Austria (Milestad, BartelKratochvil, Leitner, \& Axman, 2010), Tuscany (Galli et al., 2015), and elsewhere. They typically consist of a network of small farmers, millers, bakers, maltsters, and brewers, sustainably growing wheat and barley, often of heritage and ancient varieties, operating within local or regional supply chains, and committed to quality, craft, identity, and provenance (Halloran, 2015; Hergesheimer \& Wittman, 2012; Hills, Corbin, \& Jones, 2011; Jones \& Harvey, 2017; Steavenson, 2019).

Despite wide popular interest, most recently indicated in a New York. Times article (Wu, 2020), local grain economies are an under-researched area of alternative food networks, with only a handful of studies, mostly qualitative and descriptive, beginning in 2010. Research has explored what "local" means in the context of the grain economy
(Hills, Goldberg, \& Jones, 2013b; Milestad et al., 2010); demand and supply of local flour among commercial bakers in western Washington (Hills et al., 2013a); the embedded social and cultural value in local grain supply in British Columbia (Hergesheimer \& Wittman, 2012); the social relations in a local organic grain network in Austria (Milestad et al., 2010); the meaning of local grain to craft brewers in New England (Jones \& Harvey, 2017); the challenges of marketing ecologically grown grain in Ontario (Mann, 2016); and local bread supply chains in the UK (Smith \& Barling, 2014) and Italy (Galli et al., 2015). Yet, in line with Tregear's (2011) and Deller, Lamie, and Stickel's (2017) observation that alternative food network research lacks quantitative and structural studies, research on local grain economies to date provides little evidence of their size, structure, development, and sustainability. The lack of analysis of the evolution and properties at the whole network level makes it difficult to put the significance of the phenomenon in context, understand it from a structural perspective, and gain insight into gaps, shortcomings, trends, and possible futures.

Using the case of the local grain economy in Arizona, we address the following research questions:

1. What is the size of the local grain economy, and how did it develop?

2. What is its network structure and composition, and how did it evolve?

3. What are the impacts on the broader local economy?

4. How sustainable (economically, environmentally, socially) is it?

The case study unit of analysis is the economic network of growers, primary processors, and secondary processors in Arizona who are producing or using small grains in their production for local or regional human consumption. Due to constraints in data availability, this scope does not include distribution or general retail sectors or the many local restaurants that use small amounts of local grain products for in-house purposes.

Arizona is a suitable case for investigation due to the well-established nature of its local grain 
economy and its rapid development from 2012 to 2019. As such, this study offers a rich description of the structure and evolution of a particular local grain economy that may provide valuable insights to scholars and practitioners for accelerating similar efforts in other regions. It also offers a framework for research through a novel analytical approach combining qualitative and quantitative data and a number of analytical methods. If adopted by other researchers, coordinated comparative research may serve to fill the research gap identified above. In this article, we focus more on the quantitative aspects, whereas the qualitative results will be reported in more detail in a forthcoming article.

\section{Research Design}

\section{Analytical Framework}

Development of our analytical framework was informed by the literature on alternative food networks. Local grain economies, and related entities such as local grain networks and short grain supply chains, are a type of alternative food network. Alternative food networks, and similar concepts of short food supply chains and values-based supply chains, have arisen over the last 20 or more years in response to increasing dissatisfaction by both consumers and producers with the global, commodified agri-food industry (Renting et al., 2003; Stevenson \& Pirog, 2008). Dissatisfaction stems from various concerns, including the decline of local economies, negative environmental impacts, food safety issues, health and nutrition deficits, farmer livelihoods and small farm survival, and disconnection between consumers and producers (Renting et al., 2003; Stevenson \& Pirog, 2008). However, defining what alternative food networks are is less straightforward than identifying what they are in opposition to (Tregear, 2011).

In theory, alternative food networks are considered to be place-based and communityconnected, economically viable for all participants, ecologically sound, socially just, and democratic (Feenstra, 1997). They are local or regional in scale, composed of micro and small enterprises, and involve close connections between producers, processors, and consumers (King \& Venturini, 2005; Renting et al., 2003). They are associated with high-quality products, unique local or regional attributes, organic production, and artisan crafts (King \& Venturini, 2005; Stevenson \& Pirog, 2008). Alternative food networks are commonly claimed to create and capture additional economic value for producers and processors, and qualitative values for all (including consumers) by satisfying shared social and environmental interests (Stevenson \& Pirog, 2008).

Alternative food networks in reality, however, are more nuanced, contingent, and pragmatic (Diamond \& Barham, 2011; Mount, 2012). There is considerable heterogeneity within and between them and in the degree to which they meet sustainability criteria (Mount, 2012; Tregear, 2011). For example, the use of sustainable production methods is not universal among farmers who participate in alternative food networks, and neither is the socio-economic inclusivity of alternative food network consumers (P. Allen, 2010; Tregear, 2011). The closeness of connection between producer and consumer is often questionable (Tregear, 2011), while hybrid food businesses, which participate in both an alternative food network and the mainstream food economy, are not uncommon (Milestad et al., 2010; Mount, 2012).

Structurally, alternative food networks vary in the number and diversity of participating entities and their connections, ranging from closed, vertically integrated partnerships (e.g., a farmer cooperative) to large open networks (Renting et al., 2003; Stevenson \& Pirog, 2008). A functional alternative food network results in a range of products making their way from many varied producers, through multiple primary and secondary processors, to numerous outlets of varying types. Businesses in one sector (e.g., production) may have multiple connections to those in another (e.g., processing). Alternative food networks are dynamic, changing configuration as entities join and leave, making different connections, and extending or shortening pathways from producers to consumers (e.g., adding a processing tier). Along these lines, we sketch out the general structure of a local grain economy in Figure 1.

We drew on these alternative food network concepts in developing a framework for the analysis of Arizona's local grain economy, which com- 
Figure 1. General Structure of a Local Grain Economy Showing Core Entity Types, Identified as In- or Out-of-Scope in This Study and Scope Exceptions

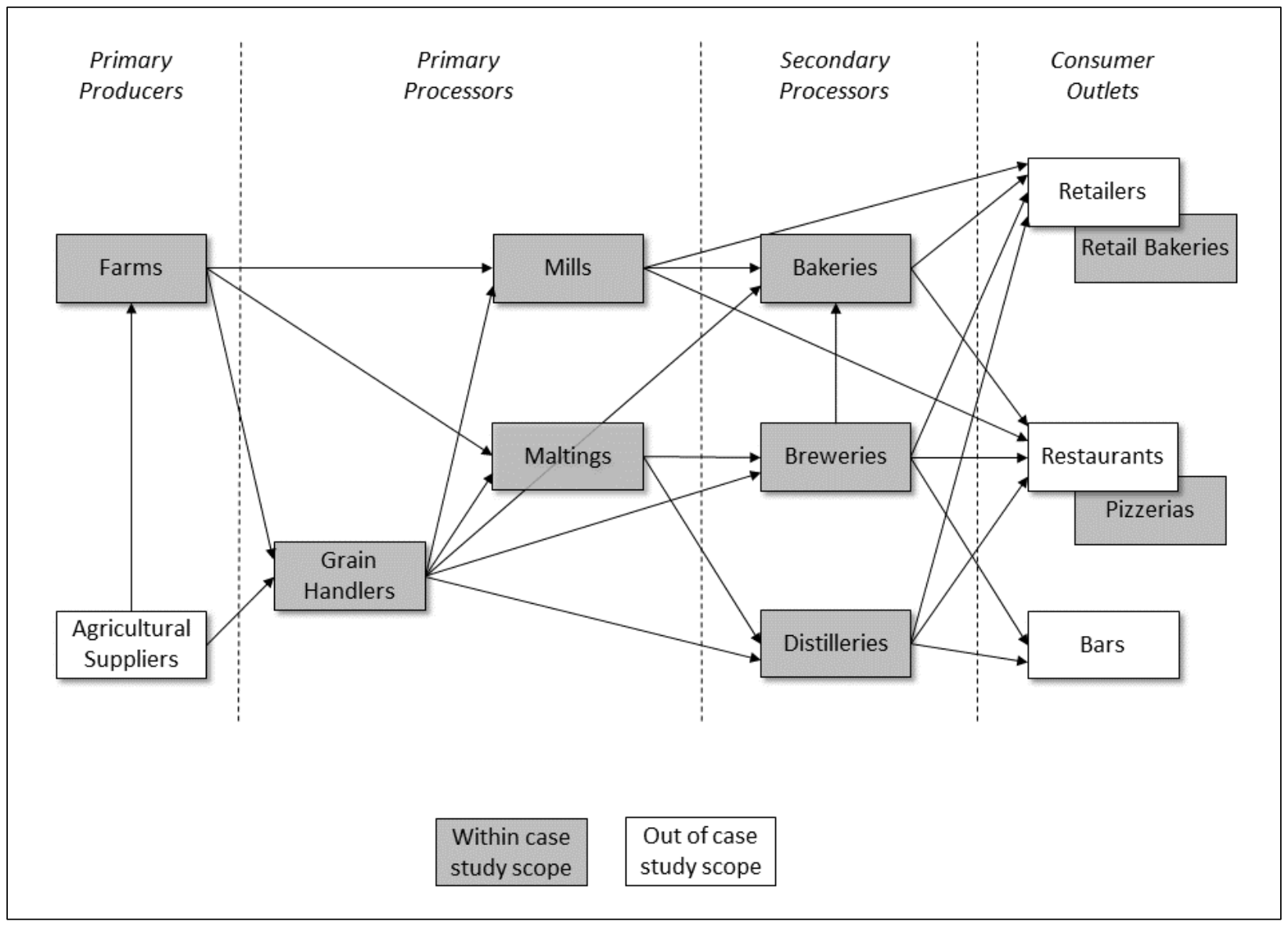

prises 14 variables and three categories of sustainability criteria, each consisting of numerous aspects (Table 1). For the purposes of this study, we define Arizona's local grain economy as the network of businesses involved in production (farms), primary processing (grain handlers, maltings, mills), and secondary processing (bread bakeries, pasta makers, pizzerias, tortillerias, breweries, distilleries, home brew stores) of small grains (wheat, barley, oats), intermediate products (clean grain, flour, malt), and end products (bread, beer, or pasta) for human consumption within a 150 -mile $(240-\mathrm{km})$ radius of central Arizona (approximating to the state of Arizona). The local grain economy is therefore distinct from the Arizona mainstream grain economy in which small grains are grown for commodity markets or the local animal feed market (Duval, Kerna, Frisvold, \& Avery, 2016).
The main reasons for focusing on production and processing is that data were not readily available for other sectors, and, at the time of this study, we were not aware of any distributors orienting their business toward local grain or derived products, while general retailers and most restaurants only use local grain or flour in small quantities relative to their total output. Some notable exceptions that we do include, however, are bakeries with retail operations and pizzerias that use significant proportions of local flour $(20 \%$ or more).

\section{Research Methods}

The research uses a single case study, combining quantitative and qualitative data to explore and gain explanatory insights into the local grain economy in Arizona. While a single case study is generally less 
valid than a comparative case study, it is justified here in that the case is "representative" and "revelatory" (Yin, 2003). It is representative as it appears to share similarities with other local grain economies, such as its grassroots origins, microscale operations, close relations between farmers, bakers, and brewers, and general alignment with the features of alternative food networks (Halloran, 2015; Hergesheimer \& Wittman, 2012; Hills et al., 2011). It is revelatory in that there is something worthy of study (an established local grain economy with an approximately 10 -year history) that has not been studied before with respect to size, structure, and evolution. The study uses a novel analytical approach, which, if adopted by other researchers, allows for comparisons with other cases, and from this, generalizing knowledge of local grain economies and alternative food networks.

Data collection was primarily guided by the research questions and analytical framework, and focused on the businesses, products, production, transactions, and developments of the local grain

\section{Table 1. Analytical Variables and Evaluative Criteria Applied to the Local Grain Economy in Arizona with Corresponding Results Section}

\begin{tabular}{|c|c|c|}
\hline Variables & Definition & Section \\
\hline Production & $\begin{array}{l}\text { Quantity and value of local small grains produced (also compared to the } \\
\text { size of the conventional grain economy) }\end{array}$ & \multirow[t]{4}{*}{ Production } \\
\hline Farm size & $\begin{array}{l}\text { The size and type of farms producing local small grains (also compared to } \\
\text { the conventional grain economy) }\end{array}$ & \\
\hline Farming Methods & The type of farming methods used & \\
\hline Business Output & Output of individual businesses in each sector & \\
\hline Retention & $\begin{array}{l}\text { Ratio of number of businesses participating in } 2019 \text { to the total number of } \\
\text { businesses that participated in at least one year between } 2012 \text { and } 2019 \\
\text { (value of 0: all businesses dropped out; value of 1: no business dropped } \\
\text { out) }\end{array}$ & \multirow[t]{8}{*}{$\begin{array}{l}\text { Structure of } \\
\text { the Economic } \\
\text { Network }\end{array}$} \\
\hline Longevity & $\begin{array}{l}\text { Ratio of the total number of businesses that participated for at least } 3 \text { of } \\
\text { the last } 4 \text { years to the total number participating in } 2019 \text { (value of } 0: \text { all } \\
\text { current business are new: value }>=1 \text { : all businesses are established } \\
\text { participants) }\end{array}$ & \\
\hline Network size & $\begin{array}{l}\text { Number of producers (farms), primary processors (grain handlers, malt- } \\
\text { sters, mills), or secondary processors (bread bakeries, pasta makers, } \\
\text { pizzerias, tortillerias, breweries, distilleries, home brew stores) }\end{array}$ & \\
\hline Diversity & Number of business categories covered and number of products & \\
\hline Geographical clustering & $\begin{array}{l}\text { Supply chain connections between businesses within a geographical area } \\
\text { (north, central, south) }\end{array}$ & \\
\hline Network density & Number and length of supply chains (links) & \\
\hline Central businesses & Businesses (network nodes) with links to many other businesses & \\
\hline $\begin{array}{l}\text { Short Supply Chain } \\
\text { Aspects }\end{array}$ & $\begin{array}{l}\text { Connections between supply chain actors and with consumers; place-based } \\
\text { food culture; food miles. }\end{array}$ & \\
\hline Local money flow & Direct and indirect financial value generation in the region & \multirow{2}{*}{$\begin{array}{l}\text { Impacts on the } \\
\text { Local Economy }\end{array}$} \\
\hline Local job creation & Direct and indirect job generation in the region & \\
\hline \multicolumn{3}{|l|}{ Sustainability Criteria } \\
\hline Economic & $\begin{array}{l}\text { Economic diversity, stability, resilience, local value and job generation, } \\
\text { business model innovation }\end{array}$ & \multirow{3}{*}{$\begin{array}{l}\text { Sustainability } \\
\text { Features of the } \\
\text { Local Grain } \\
\text { Economy }\end{array}$} \\
\hline Environmental & $\begin{array}{l}\text { Impacts of farming (soil, pollinators), renewable energy, energy efficiency, } \\
\text { water efficiency, biodiversity }\end{array}$ & \\
\hline Social & $\begin{array}{l}\text { Meaningful jobs, craftmanship, culture, ethics, wages, benefits, diversity, } \\
\text { employee ownership }\end{array}$ & \\
\hline
\end{tabular}


economy on an annual basis, as well as basic profiles and notable practices of businesses involved. We also collected additional qualitative information on participants' views on meanings, motivations, functions, challenges, and visions of the local grain economy, but do not fully report on these in this article. Data collection consisted of interviews, email correspondence, and review of secondary sources, including reports, media articles, websites, and literature, conducted between January and June 2020.

Data were collected from 19 individuals across 17 businesses and organizations (Table 2). Participants were recruited by email and follow-up phone calls. Some participants were known to the researchers through prior research. Interviewees were selected primarily for their knowledge of the local grain economy and its development, and secondarily for representativeness across sectors. The initial selection was of individuals (or businesses) known (e.g., from media reports) to have played a prominent role in the local grain economy, such as in its early development or as a central organization. Additional participants were selected by snowballing to fill gaps or broaden the representativeness, with a pragmatic cut-off when additional interviews yielded little new data. Interviews were semistructured, of 30-90 minutes duration, and content was captured through note-taking, recording, and transcription.

Supply-chain data analysis entailed reducing the data to a set of annual transactions consisting of year, source entity, destination entity, product, and quantity, modified for primary production data to ignore the source and include the area planted. As data were incomplete, inference, estimates, extrapolation, and interpolation were used to fill gaps. Gephi network graphing software (Bastian, Heymann, \& Jacomy, 2009) was used to visually plot and connect supply chain elements in a time sequence.

QDA Miner software (Lite version 2.0.7; Provalis Research) was used to code interview transcripts and notes, email texts, documents, and articles. Coding was inductive within the predefined qualitative data collection categories (meanings, motivations, functions, challenges, and visions) and underwent several iterations of consolidation and generalization. While we draw on some of the qualitative data collected in the study, particularly in the sustainability appraisal, we report the results more fully in a forthcoming publication.

As already mentioned, the study was limited by the exclusion of distributors, restaurants, and retailers, as grain products are rarely the focus of businesses in these sectors, but also because capturing their contribution is a major methodological obstacle beyond the feasibility of this study. We therefore capture the core of the local grain economy, but not its full extent. Another limit is our concentration on some aspects of the local grain economy and not others. In particular, we focused on col-

\section{Table 2. Summary of Interview Participants}

\begin{tabular}{lll}
\hline Sector & Interview Participants & Notes \\
\hline Producers & Farmers (3) & $\begin{array}{l}\text { Two others did not respond to interview request and one other } \\
\text { declined. }\end{array}$ \\
\hline Primary Processors & $\begin{array}{l}\text { Grain handler (1) } \\
\text { Millers (2) } \\
\text { Maltster (1) }\end{array}$ \\
\hline Secondary Processors & Bakers (4) & \\
& $\begin{array}{l}\text { Pasta maker (1) } \\
\text { Pizza maker (1) }\end{array}$ & One other baker cancelled due to scheduling difficulty. \\
& Brewers (5) & \\
\hline Developers & Entrepreneurs (3) & \\
\hline TOTAL & 19 individuals from 17 & Two individuals with dual roles. \\
& businesses/organizations & \\
\hline
\end{tabular}


lecting basic production data only, and not financial details, such as pricing, costs, and sales, with the exception of some primary processor aggregate sales data. The sustainability appraisal is also limited in scope by the data collected as opposed to aiming for comprehensive coverage of a sustainable economy. As such, only a little attention was paid to critical sustainability issues such as economic participation, diversity, and justice (P. Allen, 2010). Finally, some limitations of the study pertain to data completeness and accuracy. Regarding completeness, data collection was not exhaustive in terms of identifying every entity involved in the local grain economy in every year, and it is quite

\section{Figure 2. Annual Production Quantities and Area Planted in the Arizona Local Grain Economy, 2012-2019: Aggregate Total for all Small Grain Types (Top), and Totals For Wheat, Barley and Rye (Bottom)}

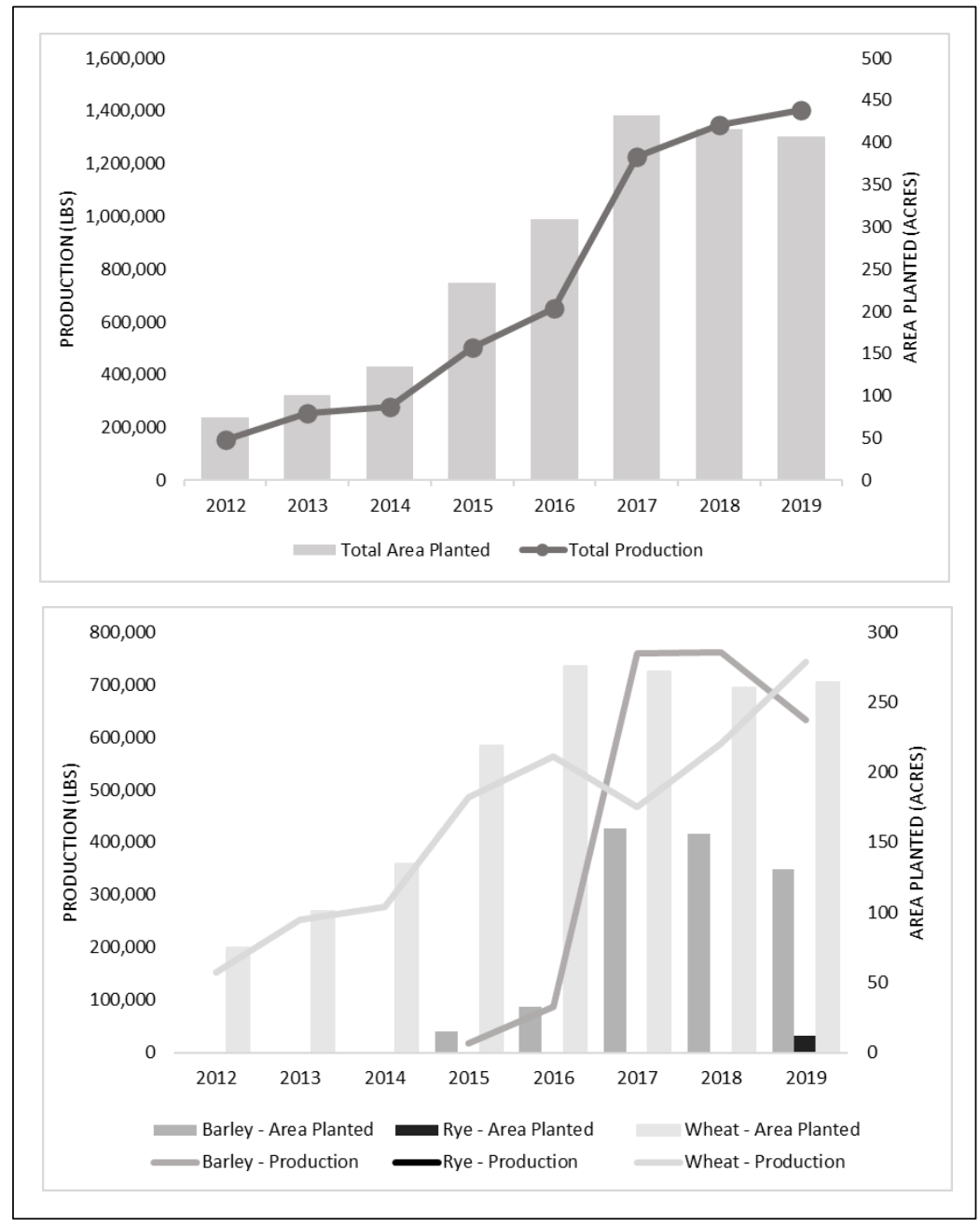

possible some were missed. Production data may also be missing due to participants being unwilling or unable to participate, non-existent or difficultto-access records, and failing memories. Using multiple sources and talking to key individuals with wide knowledge of the local grain economy reduces these possibilities, but it is quite likely the data are incomplete, and the results are underquantified. Regarding accuracy, values have been imputed for some gaps in the data, while data provided by participants were often an estimate rather than from detailed records. The data, therefore, include a margin of error.

\section{Results}

\section{Production}

\section{Production quantity}

The aggregate total area planted and production quantity of grains grown for the local grain economy increased from zero in 2011 (predevelopment phase) to over 400 acres (162 ha) and 1.4 million pounds $(635,029 \mathrm{~kg})$ in 2019 . The predominant trend has been year-to-year growth, but with some flatteningout in 2017-2019 (Figure 2). The total number of producing farms in the local grain economy has been fairly constant at between five and seven.

Looking more closely at wheat production, there is an upward trend in all categories (White Sonora, hard red, durum, and other types) from 2012 to 2019 (Figure 3). Production has been greatest for White Sonora, due to its local uniqueness and versatility, with hard red (primarily Red Fife) being next, reflecting demand by bakers for a local complement to White Sonora as they learned how to create the ideal bread-baking flour mix. Durum production, mostly Blue Beard, spiked in 2015 and 2016, as growers and processors 
Figure 3. Wheat Production Quantities in Arizona's Local Grain Economy, 2012-2019, for Major Wheat Categories

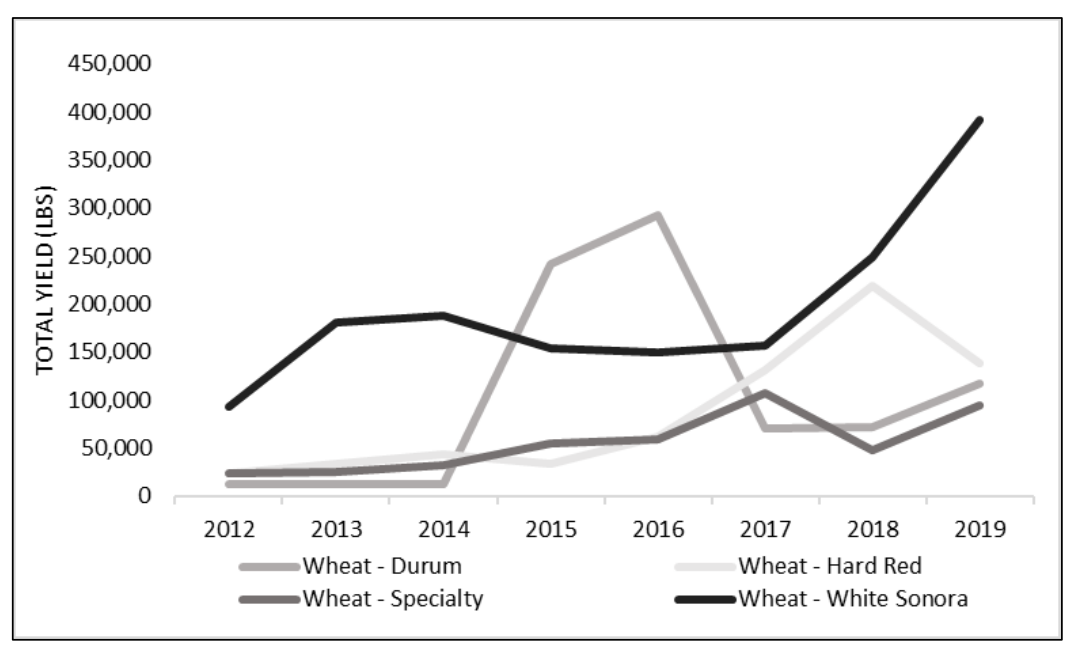

Farm size and type

Farms growing for the local grain economy have ranged in size from small (one acre, $[\sim 0.4 \mathrm{ha}])$ to medium $(4,000$ acres $[\sim 1,600 \mathrm{ha}])$, and have included locally focused organic farms, medium-sized conventional grain and feed-crop family farms, Indigenous community farms, ecovillage farms, and seedbank/conservation farms. While the total number of farms has remained between five and seven, the type has shifted from predominantly smaller, alternative growers to mostly medium-sized commercial farms of hundreds to a few were still searching for the right production levels. Other varieties, such as emmer and einkorn, make up the balance, reflecting their specialty nature. While there was experimentation with varieties in the first few years, there has been "convergence toward a smaller range" (grain handler and farmer, personal communication, January 10, 2020) in response to demand-side influence from bakers, brewers, and others, and as knowledge and experience of growing increased.

Figure 4. Arizona Small-Grains Production, 2005-2019

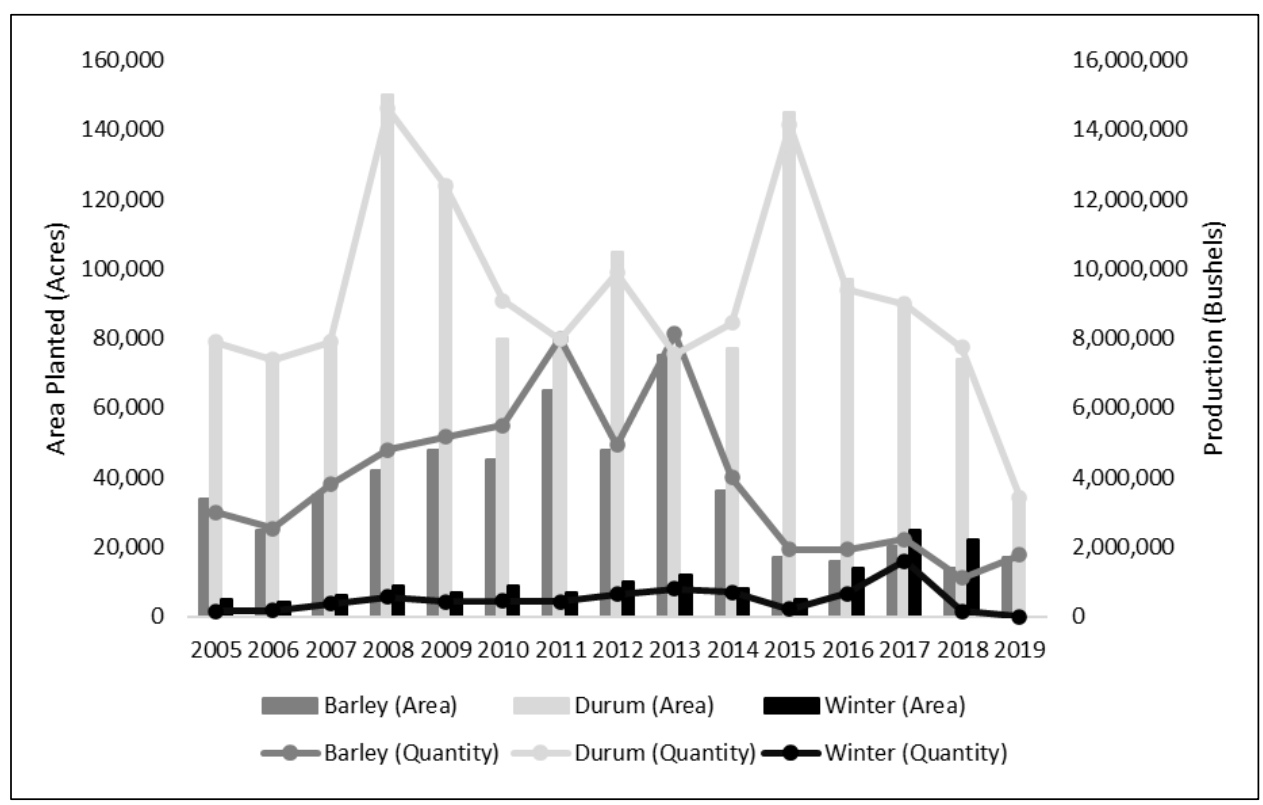

Source: NASS, 2019. production area. thousand acres. For the 2019 growers, local grain production varied from $1 \%$ to $25 \%$ of their total

\section{Comparison with mainstream production}

To put the size of local grain production in context, we compare it to the mainstream small grain economy in Arizona. Arizona has long produced sizeable quantities of barley, durum wheat, and to a lesser extent, winter wheat. From 2005 to 2018

(Figure 4), the total acres planted have ranged from 104,000 to 200,000 acres (median=134,000) (42,000-81,000 ha; $54,000 \mathrm{ha}$ ) producing between 9 and 20 million bushels (median 14) $(317,000-705,000$ $\left.\mathrm{m}^{3} ; 493,000 \mathrm{~m}^{3}\right)$ (U.S. Department of Agriculture, National Agriculture Statistics Service [USDA NASS], 2019). However, a steep decline since 2017 , likely due to commodity prices (L. Allen, 2019), has seen the 2019 acres 
planted plummet to 51,000 (21,000 ha) and just 5 million bushels $\left(176,000 \mathrm{~m}^{3}\right)$ harvested, of which winter wheat production dropped below the reporting threshold. The majority of Arizona's mainstream small-grain production is either exported out of state or sold in-state for animal feed (Duval et al., 2016). Small grains are frequently grown for crop rotation reasons, usually every three to four years, and often in combination with high value, nitrogen-fixing alfalfa feed crops (Duval et al., 2016).

In 2017 to 2019, a slight upward trend is discernable in local grain production in proportion to mainstream production (Table 3 ). The overall proportion, however, is still only one percent or less of both acres planted and production for durum, barley, and total, though notably reaching five percent for other wheat production in 2018 and 2019. The proportional increases observed, however, are more a function of the aforementioned historically low acres planted by mainstream growers in these years and the very low 2018 harvest of winter wheat than increased local grain production.

\section{Farming Methods}

The seven producing farms in 2019 included two certified organic, one practitioner of natural methods, one low-input, two conventional (high-input), and one unknown. Low-input consists of a single herbicide application in early growth. With respect to water consumption, modern small grain varieties in Arizona use roughly half the water of alfalfa, which it most commonly replaces (3 versus 6 feet, or 900 vs. $1,800 \mathrm{~mm}$ ), and heritage grains, such as White Sonora, require half of modern varieties (1.5 feet or $450 \mathrm{~mm})$. Part of the lower water use of small grains compared to alfalfa or corn is due to being spring crops rather than summer, when evapotranspiration is higher. So, for example, switching from corn to malting barley in the Verde Valley has reduced water use by $30 \%$.

\section{Business Output and Operations}

Local grain farms have outputs of tens to a few hundred tons, while the primary processors involved (mills and maltings) have similar outputs of low hundreds of tons. Bakers using local flour range in outputs from dozens of loaves per day to several thousand, and most breweries output less than a few thousand barrels per year. These are, in all sectors, two or three orders of magnitude less than mainstream grain industry producers and processors. The small batches involved and the size of available equipment, whether it is for harvesting, cleaning, milling, malting, or baking, results in suboptimal water and energy efficiency in operations. Despite their apparent awareness of high water and energy use, few businesses have introduced resource-efficiency measures such as solar energy or water reclamation, although there are notable exceptions, such as Grain R\&D's extensive solar installation.

Regarding future output, we found that many businesses expressed a desire for some growth, primarily for reasons of business stability. Almost all, however, would like to see the local grain economy grow through new businesses, again, partly for reasons of business stability (e.g., supply reliability), but also for the wider benefits provided.

\section{Structure of the Economic Network}

\section{Retention and Longevity}

The network of local businesses that grow, process, and otherwise work with local grains in Arizona has increased in size from 12 businesses in 4

Table 3. Local Small Grain Production as a Percentage of Mainstream Small Grain Production in Arizona

\begin{tabular}{lccccccccc}
\hline Year & \multicolumn{3}{c}{ Acres Planted } & \multicolumn{4}{c}{ Production Quantity } \\
\hline & Durum & Other Wheat & Barley & Total & Durum & Other Wheat & Barley & Total \\
\hline 2017 & $<0.1 \%$ & $1.0 \%$ & $0.8 \%$ & $0.3 \%$ & $<0.1 \%$ & $0.4 \%$ & $0.6 \%$ & $0.2 \%$ \\
\hline 2018 & $<0.1 \%$ & $1.0 \%$ & $1.1 \%$ & $0.4 \%$ & $<0.1 \%$ & $5.4 \%$ & $1.1 \%$ & $0.2 \%$ \\
\hline 2019 & $0.1 \%$ & $>1.0 \%$ & $0.8 \%$ & $0.7 \%$ & $0.1 \%$ & $>5.0 \%$ & $0.6 \%$ & $0.4 \%$ \\
\hline
\end{tabular}

Source: Mainstream data from NASS (2019). 
categories in 2012 to 45 businesses in 11 categories in 2019, or 47 if BKW's triple farming, grain handling, and milling operations are counted separately (Table 4). The largest increases are seen in secondary processors, with bakeries, pizzerias, and pasta makers growing from four to 11 , and breweries and distilleries from two to 24 , while primary processors have grown to five since the first mill started operating in 2012 (again, noting that BKW's grain handling and milling are counted separately). In contrast, the number of small-grain growers has changed little, fluctuating between five and seven.

Retention and longevity indices indicate the turnover and long-term stability of participating businesses (Table 4). Production exhibits moderately low retention (0.4), with 10 farms no longer participating out of a total of 17 (after excluding two seed-purchasing but nonproducing farms), but also moderately high longevity (0.6), with six of the current seven producing farms being long-term participants. This reflects a number of farms that experimented, especially in the period 2012-2016, but a hardening of the supply chain in more recent years around market demand and a core group of growers, mostly larger farms, with the capacity to reliably meet that demand. The primary processing sector shows high retention (1.0), with no dropouts, and high stability (1.0), with all four participants (five when BKW grain handling and milling are counted separately) active over the most recent four years. In the secondary processing sector, the artisan bread bakeries show high retention (0.8) and longevity (0.8), with three of the five participating bakeries in 2019 being steady participants since at least 2016, the other two being newer entrants in 2018, and one other with long-term although irregular participation, being out in 2019. The overall bakery sector has expanded in the last two years, adding pizzerias, pasta makers, and tortillerias (indicated by longevity of 0.5 ), yet remarkably high retention (0.9), with only one business dropping in and out over the years. The breweries and distilleries sector (including homebrew stores) shows moderately high retention (0.7), with 24 of 35 businesses currently participating, but low longevity (0.2), with only five long-term participating businesses. This is primarily due to a large number of breweries and distilleries experimenting with local grains and malt in the last two years. Over all sectors, retention is moderate-high (0.7), indicating

Table 4. Number and Types of Businesses in the Arizona Local Grain Economy, 2012-2019

\begin{tabular}{|c|c|c|c|c|c|c|c|c|c|c|c|}
\hline Business Type & 2012 & 2013 & 2014 & 2015 & 2016 & 2017 & 2018 & 2019 & Total & Retentio & ngevity \\
\hline Farms & 7 & 8 & 7 & 8 & 7 & 5 & 6 & 7 & 19 & 0.4 & 0.6 \\
\hline Primary Processors & 1 & 1 & 4 & 4 & 5 & 4 & 5 & 5 & 5 & 1.0 & 1.0 \\
\hline Grain Handlers & 0 & 0 & 2 & 2 & 2 & 2 & 2 & 2 & 2 & 1.0 & 1.0 \\
\hline Maltings & 0 & 0 & 0 & 0 & 1 & 0 & 1 & 1 & 1 & 1.0 & 1.0 \\
\hline Mills & 1 & 1 & 2 & 2 & 2 & 2 & 2 & 2 & 2 & 1.0 & 1.0 \\
\hline Bakeries & 4 & 4 & 5 & 5 & 5 & 5 & 10 & 11 & 12 & 0.9 & 0.5 \\
\hline Bread Bakeries & 3 & 3 & 4 & 4 & 4 & 4 & 6 & 5 & 6 & 0.8 & 0.8 \\
\hline Pasta Makers & 0 & 0 & 0 & 0 & 0 & 0 & 0 & 1 & 1 & 1.0 & 0.0 \\
\hline Pizzerias & 1 & 1 & 1 & 1 & 1 & 1 & 2 & 2 & 2 & 1.0 & 0.5 \\
\hline Tortillerias & 0 & 0 & 0 & 0 & 0 & 0 & 2 & 3 & 3 & 1.0 & 0.0 \\
\hline Breweries \& Distilleries & 0 & 2 & 9 & 4 & 5 & 5 & 15 & 24 & 35 & 0.7 & 0.2 \\
\hline Breweries & 0 & 2 & 9 & 4 & 5 & 5 & 14 & 18 & 29 & 0.6 & 0.3 \\
\hline Distilleries & 0 & 0 & 0 & 0 & 0 & 0 & 1 & 4 & 4 & 1.0 & 0.0 \\
\hline Home Brew Stores & 0 & 0 & 0 & 0 & 0 & 0 & 0 & 2 & 2 & 1.0 & 0.0 \\
\hline TOTAL & 12 & 15 & 25 & 21 & 22 & 19 & 36 & 47 & 71 & 0.7 & 0.4 \\
\hline
\end{tabular}

Notes: (1) the number of farms counted in 2018 and 2019 includes one in each year that purchased seed but were nonproducing in terms of output to the network; (2) One business (BKW) has distinct farming, grain handling, and milling operations that are counted separately. 
considerably more businesses currently participate than have dropped out over the eight-year period, with lower longevity (0.4) reflecting a modest but stable core and relatively large number of newer participants.

\section{Network Size and Diversity}

Diversity of both businesses and products increased over time (Table 5). In 2012, there were a handful of mainly small farms growing primarily White Sonora, very limited grain handling facilities, a rudimentary milling operation, and three bakeries. In 2019, five larger farms were growing around 10 varieties of wheat and barley, two dedicated grain handling facilities were in operation, two craft milling and one malting business had been established producing a broad range of value-added and packaged grain products, and almost 40 secondary processing businesses were using local grain ingredients to produce a wide variety of baked goods, beers, and spirits. This account does not include the dozens of restaurants, numerous small stores, and several supermarkets that also regularly use end products from mills and grain handlers.

Some other facets of the local grain economy, however, show low diversity. The corporate form of all businesses that have participated in the local grain economy is dominated by conventional, forprofit forms of limited liability companies $(67 \%)$, general corporations $(20 \%)$, and limited liability partnerships (4\%). Two nonprofit corporations participated in the early years, and one (for-profit) benefit corporation is still active. The size of businesses involved in most sectors is in the micro to very small range, most with fewer than 10 employees and many with fewer than five. The exceptions are a few larger breweries with restaurant operations that have over 50 staff. Regarding the racial, ethnic, and gender diversity of people involved in the local grain economy, we did not formally collect data, but from observation we believe it is safe to say it is predominantly white and male. Notable exceptions though, include two Indigenous community producers, a second-generation Asian producer/processor, and Latino bakers, particularly since the recent uptake by tortillerias.

Network Density, Clustering, and Centrality

The current state of the economic network

(Figure 5) can be described using network metrics

Table 5. Change in Diversity of the Local Grain Economy in Arizona Between 2012 and 2019

\begin{tabular}{|c|c|c|c|}
\hline Sector & $\begin{array}{l}\text { Business / } \\
\text { Products }\end{array}$ & 2012 & 2019 \\
\hline \multirow[t]{2}{*}{ Production } & Growers & $\begin{array}{l}6 \text { micro to small community farms and } \\
1 \text { larger family farm, ranging from } 1- \\
700 \text { acres }(0.4-283 \mathrm{ha})\end{array}$ & $\begin{array}{l}8 \text { small to medium family and Indigenous } \\
\text { community farms ranging from } 50 \text { to } 4,000 \\
\text { acres }(20-1,619 \mathrm{ha})\end{array}$ \\
\hline & Grain Varieties & $\begin{array}{l}3 \text { Wheat: White Sonora, Emmer, Red } \\
\text { Fife }\end{array}$ & $\begin{array}{l}6 \text { Wheat: White Sonora, Red Fife, Rouge } \\
\text { Bordeaux, Emmer, Einkorn, Khorasan } \\
2 \text { Durum Wheat: Blue Beard, Desert } \\
3 \text { Barley: Purple Barley, Bronze Barley, Copeland }\end{array}$ \\
\hline \multirow[t]{2}{*}{$\begin{array}{l}\text { Primary } \\
\text { Processing }\end{array}$} & Businesses & 1 micro mill & $\begin{array}{l}2 \text { small mills, } 1 \text { bakery with an integrated micro } \\
\text { mill } \\
2 \text { grain handlers (cleaning, storage) } \\
1 \text { malting }\end{array}$ \\
\hline & $\begin{array}{l}\text { Ingredient- } \\
\text { Products }\end{array}$ & Small variety of flours (see above) & $\begin{array}{l}\text { Large variety of flours (see above) } \\
\text { One base malt }\end{array}$ \\
\hline \multirow[t]{2}{*}{$\begin{array}{l}\text { Secondary } \\
\text { Processing }\end{array}$} & Businesses & 3 small bakeries, and 1 pizzeria & $\begin{array}{l}5 \text { bakeries ( } 1 \text { micro, } 3 \text { small, } 1 \text { medium) } \\
2 \text { pizzerias, } 3 \text { pasta makers, } 3 \text { tortillerias } \\
18 \text { breweries, } 4 \text { distilleries, } 2 \text { home brew stores }\end{array}$ \\
\hline & End-Products & Bread & $\begin{array}{l}\text { Bread, Pizza, Pasta, Wheat berries, Tortillas } \\
\text { Beer, Spirits }\end{array}$ \\
\hline
\end{tabular}


from graph theory. The density (measure of connectedness among all nodes or businesses) is very low at $2 \%$, the average degree (number of connections of each node) is also low at 1.12, and the average path length is short, at 1.79 , compared to the maximum of 3 . These numbers express what is visually apparent: that most nodes or businesses have only a single connection and go through two or three links to connect to other nodes or businesses. This is expected, knowing that the grain usually goes through the primary processors (grain handlers, mills, maltings) to get to secondary processors. There are, however, some instances of grain going direct from farm to secondary processor (one link), such as unmalted White Sonora being used in wheat beers, or bakers using whole grains in multigrain loaves. For the most part, however, the centralization of the network around four star-shaped nodes is clear, showing that almost all of the supply-chain paths go through one (or two) of these four nodes, and as such, they are critical links in the economy.

There are three supplychain types: (i) grower $\rightarrow$ secondary processor; (ii) grower $\rightarrow$ primary processor $\rightarrow$ secondary processor; and (iii) grower $\rightarrow$ primary processor $\rightarrow$ primary processor $\rightarrow$ secondary processor. When retailers or restaurants are appended to these chains, as outlets for products such as wholesale bread, packaged flour, or beer, supply chains can extend to four links. There is some local centrality, meaning that many of the growers or secondary processors connect to only one of the primary processing centers, but there are some that connect to more than one. We see, for example, some brewers obtaining supplies from both malting and grain handler, and bakers obtaining supplies from both mills. This local centrality is somewhat geographically clustered (Figure 5): around Tucson in the south, Phoenix in the center, and Verde Valley/Flagstaff in the north, indicating that secondary processors have some affinity for local processors. Yet, for the most part, processors supply end-producers all over the state.

\section{Short Supply Chain Aspects}

The possibility of making personal connections within the supply chain was given by $25 \%$ of interviewees as a motivation to participate in the local grain economy. This extended to making connections to consumers in order to build, and be supported by, community (mentioned by $20 \%$ of interviewees as important functions of the local grain economy). There was also a strong indication from interviewees that creating a culture and identity around local food, particularly heritage grains, was of high importance, with significant appreciation for White Sonora's historical connections. The extent to which this is shared by customers, however, is less clear.

\section{Figure 5. The Local Grain Economic Network in Arizona, 2019}

Four main business categories are shown in different colors using an adjusted geospatial layout in Gephi network analysis tool (Bastian et al., 2009). Nodes are not in their exact location and the Arizona geographical overlay is indicative only. Out-of-state entities are: $A=$ Malting, $B=$ Brewery, $C=$ Bakery, $D=$ Mill, $E=$ Farm.

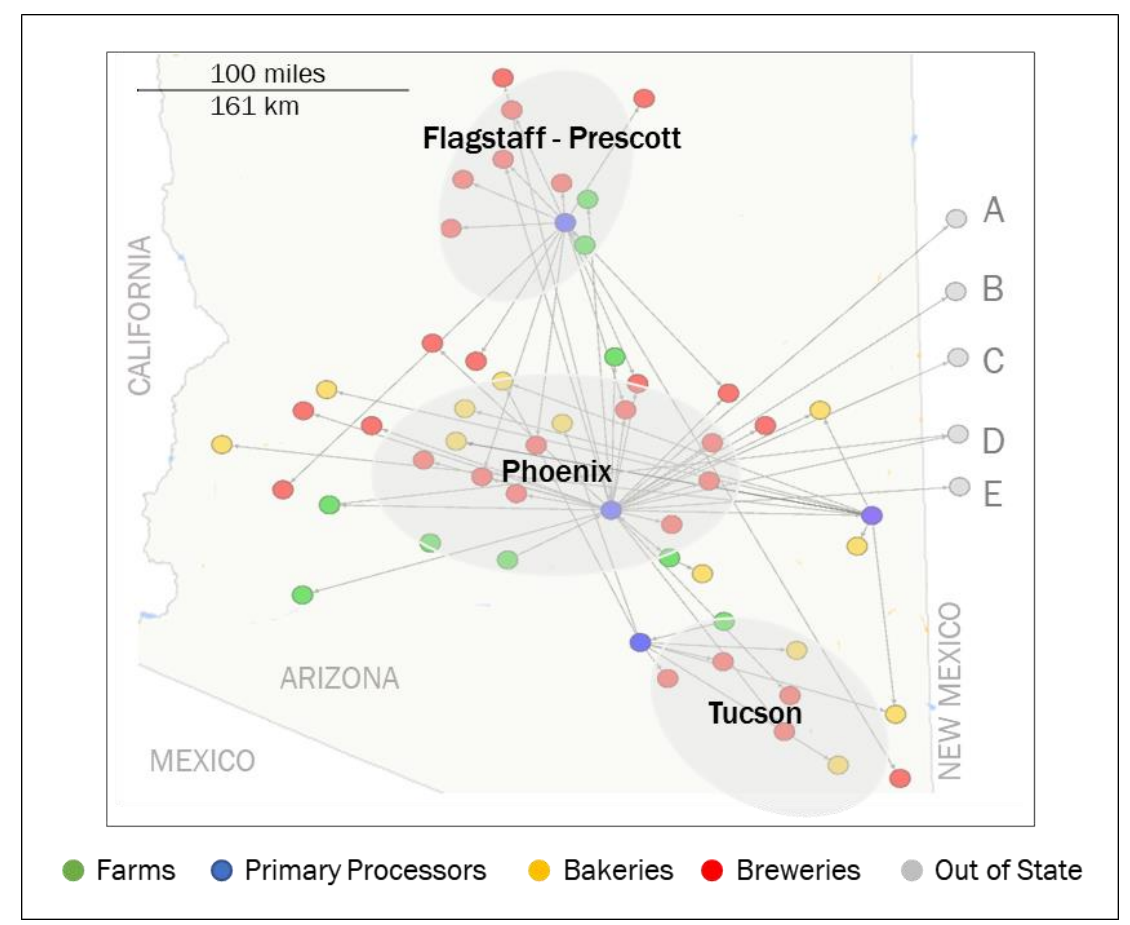


Another aspect, seen as important by $20 \%$ of interviewees, is that the physically short supply chains reduces food miles. This replaces flour and

\section{Figure 6. Year-by-Year Development of the Local Grain Economic Network in Arizona, 2012-2019}

Four main business categories are shown in different colors using an adjusted geospatial layout in Gephi network analysis tool (Bastian et al., 2009). Out-of-state entities are: $\mathrm{A}=$ Maltster, $\mathrm{B}=$ Brewery, $\mathrm{C}=$ Bakery, $\mathrm{D}=$ Mill, $\mathrm{E}=$ Farm. Longitudinal arrows demarcate early development, consolidation, and expansion stages.

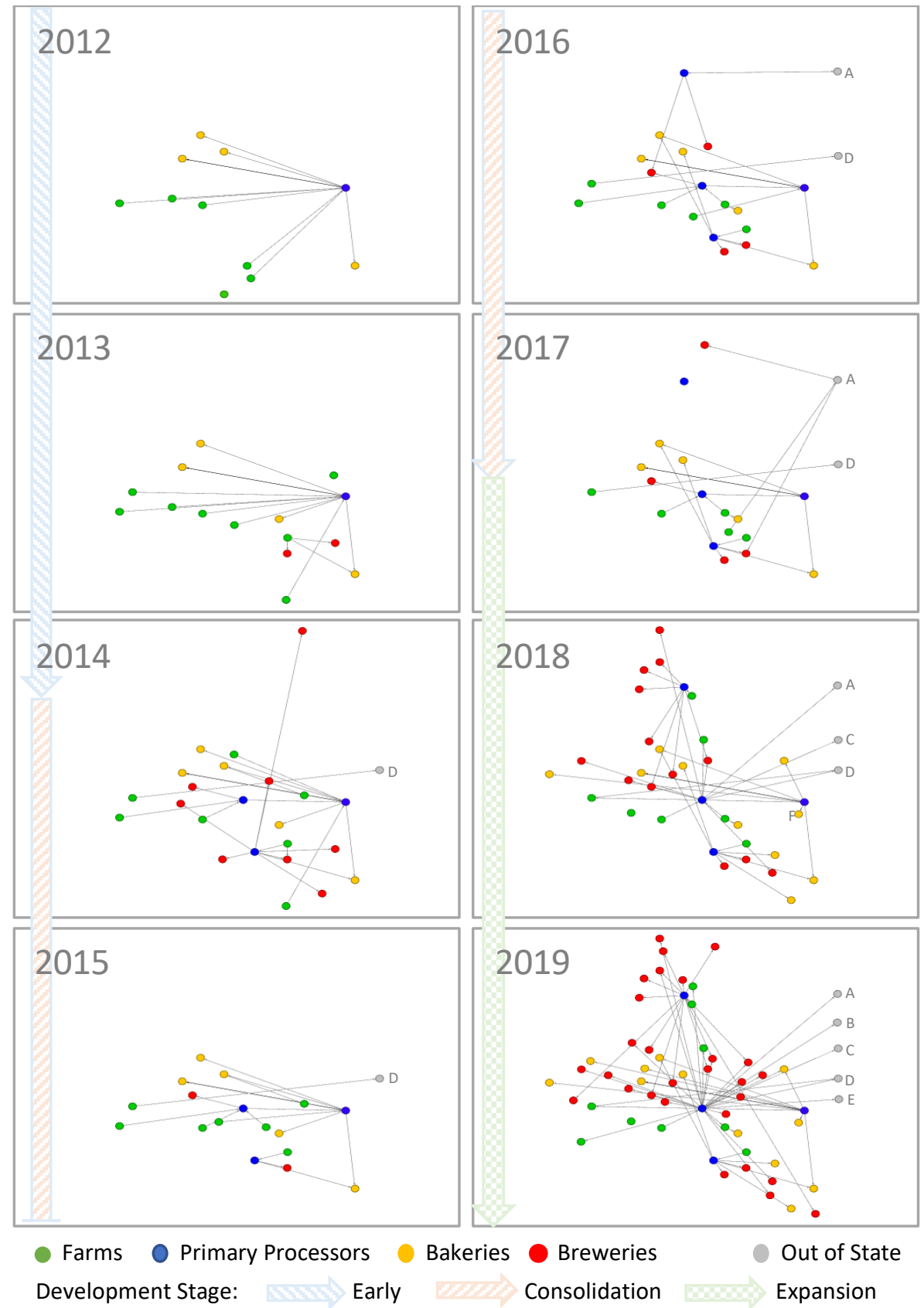

wheat previously shipped 1,000 miles $(1609 \mathrm{~km})$ or more from mills and growers mostly in western U.S. states, and malt shipped 2,000 miles $(3218 \mathrm{~km})$ from midwestern maltings and Canadian growers. Due to the relatively low volumes and logistics involved in local grain distribution, however, the associated greenhouse gas emissions reductions might be offset to some extent by less-efficient smaller vehicles and lower loads.

\section{Development of the} Economic Network We tentatively identified four stages in the development of the economic network (Figures 6 and 7), described below with key activities marked in italics.

\section{Early Development (2012-2014)}

In the first stage, development happened around one central node, the initial mill in Phoenix (Hayden Flour Mill), which provided a first critical link between growers and bakers. Key activities and supporting factors in this stage included: (i) the formation of a core group of transformational entrepreneurs, consisting of a miller, a restaurateur, an artisan baker, and a farmer; (ii) support from the Arizona-based seed conservation organization, Native Seed/SEARCH (NS/S), with US $\$ 50,000$ USDA funding, who led a 


\section{Figure 7. Development Stages of the Local Grain Economic Network in Arizona with Key Activities and Primary Type of Actor Performing Them}

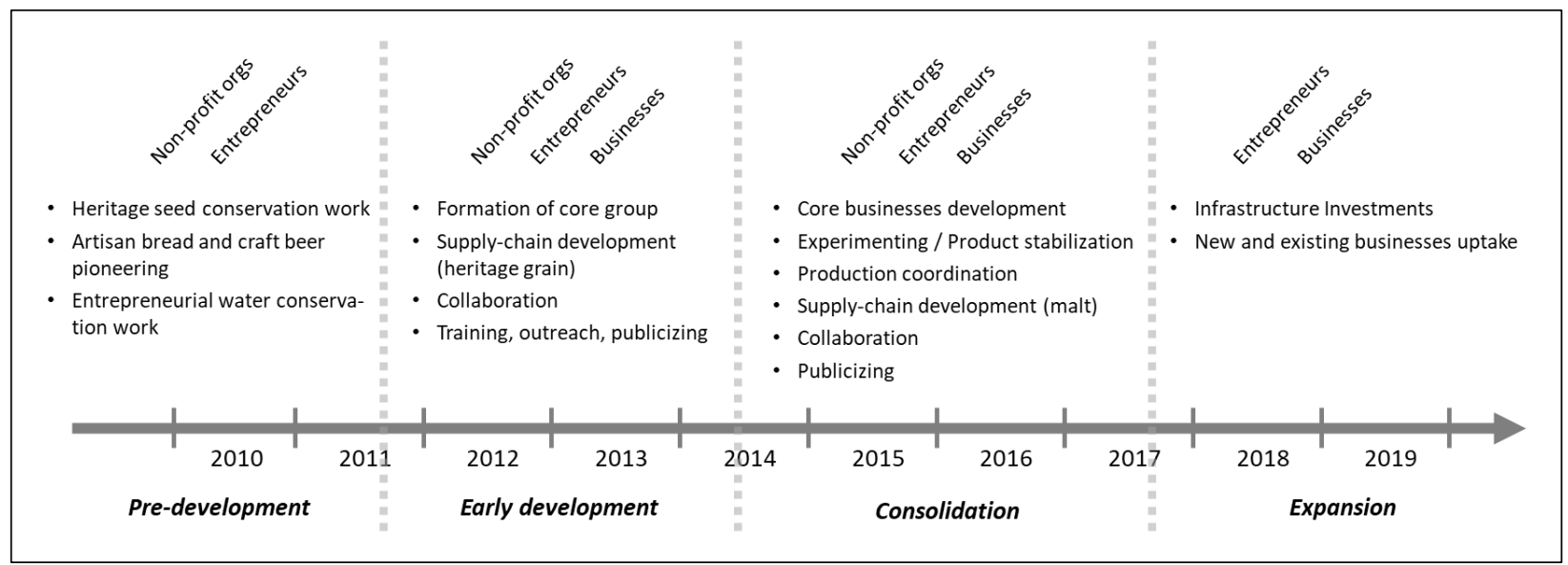

supply-chain development project to create an initial constellation of growers, millers, bakers, and chefs to simultaneously develop the demand and supply sides around the startup milling operation; (iii) collaboration between the aforementioned entrepreneurs involving openness, resource and information sharing, experimenting, and learning tacit skills from each other; and (iv) performing training, outreach, and publicity activities to build capacity in growers and bakers, and grow the market.

\section{Consolidation (2014-2017)}

Two additional central nodes started in this stage: a Phoenix grain handling operation (Grain $R \& D$ ) and an integrated grain handling and milling center in the Tucson area (BKW). Many supply-chain paths now became three links with two primary processing steps (producer $\rightarrow$ primary processor $\rightarrow$ primary processor $\rightarrow$ secondary processor). A fourth central node, the Sinagua Malt malting in the Verde Valley, 90 miles $(146 \mathrm{~km})$ north of Phoenix, also began to emerge. Key events and activities in this phase included: (i) business development of Hayden Flour Mill (including online retail) and Barrio Bread, an artisan bakery in Tucson, funded by separate USDA grants of US $\$ 100,000$ each; (ii) experimenting with new varieties requested by bakers and brewers, leading to stabilization of products (e.g., grain varieties, flour mixes), and, with some production coordination among growers by Grain R\&D, finding an equilibrium between supply and demand; (iii) breweries experimenting and beginning to regularly use (unmalted) White Sonora; (iv) a second, unrelated, supply-chain development project to develop demand and supply sides for malted barley, conducted by The Nature Conservancy and a group of transformational entrepreneurs; and (v) collaboration and experimentation in a pilot project to grow barley in Arizona, malt it out of state, transport it back to Arizona, and brew experimental beers; and (vi) continued prominent national and regional publicity.

\section{Expansion (2017-2019)}

In the third stage, the four processing operations were prominent hubs in the network, and the number and types of secondary processors significantly expanded. Key activities and events were: (i) major investment in infrastructure, including US $\$ 2 \mathrm{M}$ in grain handling and milling facilities by Grain R\&D and Hayden Flour Mill, and US $\$ 0.8 \mathrm{M}$ for Sinagua Malt's malting facility; and (ii) significant uptake of local grain by existing businesses, particularly breweries and distilleries, and new businesses (bakeries, tortillerias, pizzerias, pasta makers) forming around the use of local grains as a core feature.

\section{Predevelopment (pre-2012)}

Predevelopment and contextual aspects were also important in the network development. Contextually, Arizona's hot desert climate and the availability of irrigated water makes it suitable for growing 
specialty wheats, like khorasan, that originated in a similar climate, while White Sonora is a uniquely desert-adapted variety with a 400 -year history in the region. Large areas of agricultural land in proximity to two large cities (Phoenix and Tucson) with strong local food cultures and direct sales channels are enabling factors for the local grain economy in particular and for alternative food networks in general (Hills et al., 2013b).

Important predevelopments include the extensive work of seed conservationists and revivalists, Glenn Roberts (Anson Mills) and Gary Nabhan (NS/S), whose knowledge, experience, and seed bank were essential for the development of the local grain economy in Arizona. Another is the rise in interest and demand for artisan bread and craft beer which created a market for the local grain products while driving development of the network through participation of passionate, curious, and skilled bakers and brewers. A third early factor, out of which Sinagua Malt grew, were the several years of groundwork by The Nature Conservancy in Central Arizona to find innovative, multistakeholder, entrepreneurial solutions to water conservation.

\section{Impacts on the Local Economy}

\section{Figure 8. Changes in Money Flows in the Local Grain Economy in Arizona, Pre-2012 and 2019 (DTC=Direct to Consumer)}
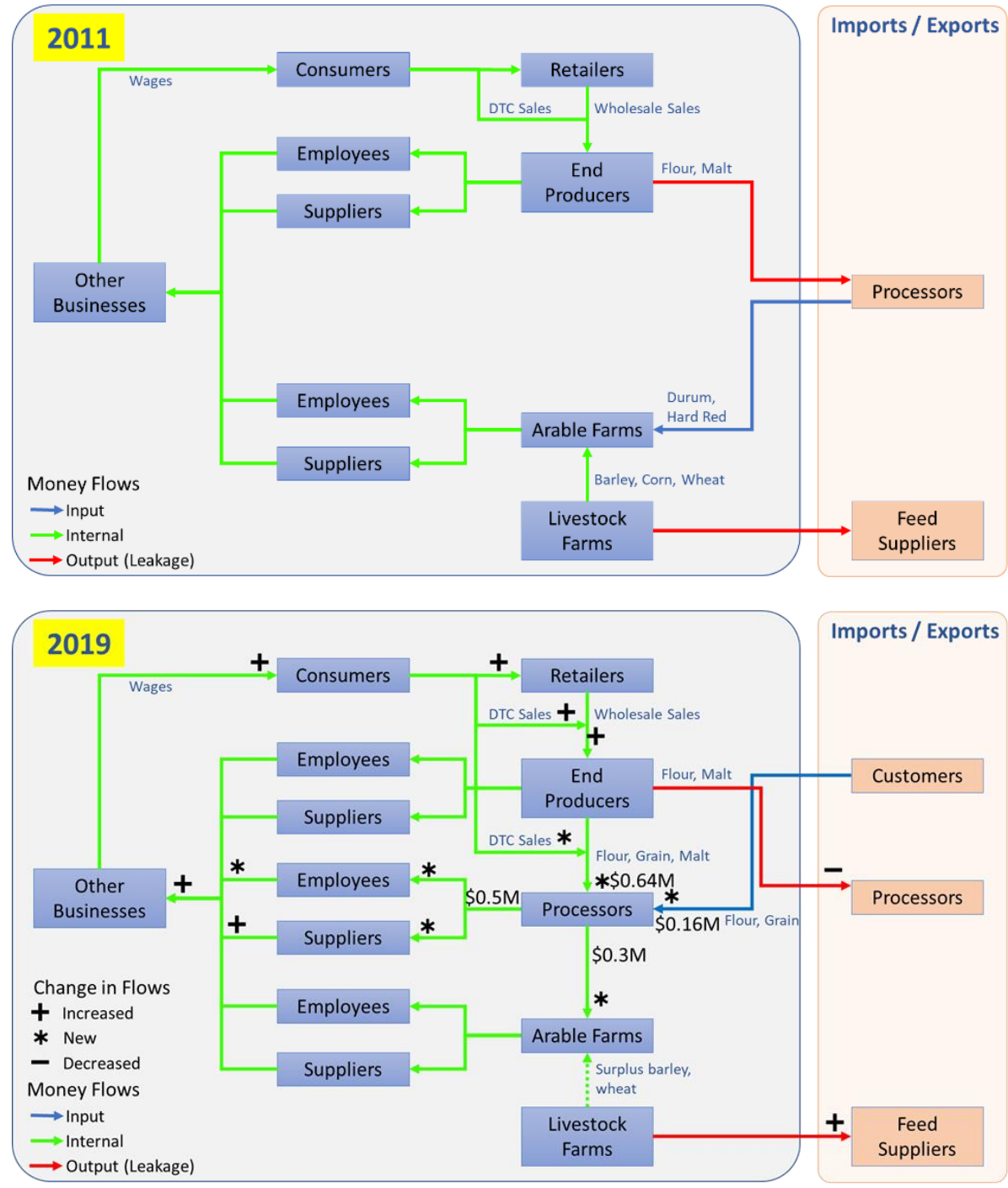

Local money flow and job creation

With the growth of the local grain economy, secondary processors and direct consumers have redirected some expenditures on grain, flour, and malt to the new primary processors (grain handlers, mills, maltings), which also receive revenue from out-of-state sales (Figure 8). The processors' aggregate total revenue in 2019 is estimated at US $\$ 800,000$, of which $20 \%$ is from exports. Thus, US $\$ 640,000$ is money that would have left the state, and US $\$ 160,000$ is new money coming into the state. The processors spend that income on grain from local farms, other suppliers, employee costs, and taxes. We estimate that US $\$ 300,000$ is paid to farmers, replacing income they would receive from local livestock farms for feed barley or corn, or from conven- 
tional durum wheat exports, in the absence of demand for sustainably grown heritage grains and malted barley (farmer, personnel communication, February 10, 2020). This is not new money for these farms; it is replacing their previous earnings from livestock farmers, who, we assume, are now increasing imports of feed by the same amount (although some of the demand may have switched to other in-state farms). The processors are assumed to spend the US $\$ 500,000$ balance on local supplies, wages, and taxes. This is new money being kept in the state. Secondary and tertiary transactions by suppliers and their employees keep some percent of this new money in-state as well, including some of it being spent on local grain endproducts (beer, bread, pizza, etc.). Thus, there is a boost to the overall Arizona economy, and even to the local grain economy, however small, from the increased money circulation in the state.

Similar to the money flow, it is the jobs created by the primary processors that can be considered new jobs. For farms, the labor demand was unchanged: farms are still growing crops, albeit different ones. Secondary processors (bakeries, breweries, etc.) have the same labor demand: they are still baking bread or brewing beer, albeit with different flour or malt. We estimate a total of 10 jobs have been directly created by 2019 . Some are minimum wage, a few tend toward "unskilled" labor, while several are skilled craft jobs (millers, maltsters), and all require learning much about the new grain economy. There is also some augmentation with free labor by entrepreneurs.

Duval et al. (2016) put the total value of conventional Arizona small grains agriculture sales in 2014 at US\$104 million and estimated a multiplier effect for the mainstream small-grain economy through economic input/output analysis of 2.0, or a total of US\$206 million of sales in the state including indirect and induced expenditure. They also estimated a jobs multiplier of 1.8 (814 direct jobs and 671 secondary). There are significant differences between the mainstream small-grain producers of Duval et al.'s (2016) study and the local grain processors of our study, including being in different supply-chain sectors, and therefore, significant differences in multiplier effects are likely. Notwithstanding such differences, it is still useful to apply Duval et al.'s (2016) multiplier effects to the local grain economy in Arizona as a first-order approximation. Doing so suggests that the local grain economy has boosted sales by US $\$ 1 \mathrm{M}(2.0$ * US $\$ 500,000)$ and jobs by $18(1.8 * 10)$ in total across all sectors.

Numerous additional indirect jobs may have been created as bakeries and breweries have expanded and new ones have started. While local breweries, bakeries, and restaurants clearly drive demand for local grain, it is not clear the extent to which local grain supply is driving growth in these secondary processing businesses: they may have grown or have been started whether they use local grain or not. However, some of the businesses make local grain a prominent "unique selling proposition." All the businesses, whether explicit or not in their marketing, may benefit from producing unique and quality products made possible by local grains. Local grains therefore may also be credited with contributing to the growth of secondary processing businesses.

Interviewees clearly see contributing to the local economy as an important part of what they do, with $25 \%$ mentioning it as a key characteristic of the local grain economy and $40 \%$ stating it as a reason why they choose to grow or use local grain. Keeping money in the local economy was the common refrain, with a concern for farmer livelihoods and a desire to see money more evenly distributed across the supply chain also frequently mentioned. However, there was little mention of the jobcreation aspects and no mention of improving employment conditions for farm workers or other minimum-wage workers in the food sector.

\section{Sustainability Features of the Local Grain Economy}

The local grain economy seems now well established in Arizona, with hundreds of acres under production, yielding hundreds of tons of welladapted grain varieties and involving dozens of well-connected small businesses that produce a variety of quality local products for a growing consumer base. Below, we synthesize the results presented in the sections above to offer an initial, though limited, appraisal of the local grain economy's sustainability (Table 6).

To summarize, it seems the local grain econ- 
omy in Arizona is having positive sustainability impacts, with some clear economic, environmental, and social benefits, although there is room for improvement.

\section{Discussion}

While the local grain economy in Arizona has grown in size, diversity, and sustainability efforts since its inception in 2012, there are a number of critical issues that warrant closer scrutiny as they are of relevance to the development of local grain economies in other regions, too.

Impact. The total local grain production, and in most grain categories, is currently (2019) less than one percent of total grain production in Arizona, even though conventional production is at its lowest level in 15 years. Clearly, the impact compared to conventional grain economy outputs is small. Yet, it would be misleading to gauge the impact of

Table 6. Sustainability of the Local Grain Economy in Arizona, 2019

\begin{tabular}{|c|c|c|c|}
\hline & Economic Features & Environmental Features & Social Features \\
\hline 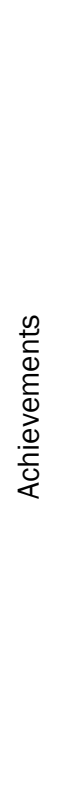 & $\begin{array}{l}45 \text { local businesses (partially) } \\
\text { build their operations around local } \\
\text { grain, covering all sectors and } \\
\text { business categories. } \\
\text { Many businesses, particularly in } \\
\text { production, processing, and baking } \\
\text { sectors show stability over the last } \\
\text { four years. } \\
\text { Ca. } \$ 0.5 \mathrm{M} \text { annually added to the } \\
\text { Arizona economy with another } \\
\$ 0.5 \mathrm{M} \text { added through local } \\
\text { multiplier effects. } \\
10 \text { jobs directly created in } \\
\text { processing sector, with an } \\
\text { estimated } 8 \text { more created in the } \\
\text { wider Arizona economy. } \\
\text { Numerous additional indirect jobs } \\
\text { may have been created through } \\
\text { expansions and start-ups of } \\
\text { bakeries and breweries. }\end{array}$ & $\begin{array}{l}\text { Most farmers practice organic, } \\
\text { natural, or low-input farming. For } \\
\text { some, the switch to local grain } \\
\text { reduced pesticide and herbicide } \\
\text { use. } \\
\text { Local grains need less water than } \\
\text { the crops they replaced (e.g., White } \\
\text { Sonora needs only 50\% of the } \\
\text { water than conventional wheat). } \\
\text { Switching to barley in the Verde } \\
\text { Valley has helped restore Verde } \\
\text { River flows. } \\
\text { Re-establishing (locally extinct) } \\
\text { heritage grains increases } \\
\text { agricultural biodiversity. } \\
\text { Food miles have been vastly } \\
\text { reduced from thousands to mostly } \\
\text { less than one hundred. }\end{array}$ & $\begin{array}{l}\text { Meaningful skilled jobs created in } \\
\text { primary and secondary processing } \\
\text { businesses. } \\
\text { Revival of artisan crafts in the food } \\
\text { economy. } \\
\text { Strengthening of social relations } \\
\text { among supply chain participants } \\
\text { and consumers. } \\
\text { Development of a strong culture } \\
\text { around local grains as well as } \\
\text { rebuilding historical ties (e.g., } \\
\text { White Sonora). } \\
\text { Appreciation for the ethical trade } \\
\text { aspects of the network, making } \\
\text { sure that farmers are adequately } \\
\text { supported. }\end{array}$ \\
\hline 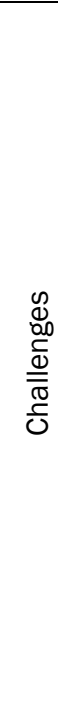 & $\begin{array}{l}\text { Many businesses are micro or } \\
\text { small in scale making them very } \\
\text { vulnerable to shocks (sickness, } \\
\text { turnover, pandemic, etc.). } \\
\text { Diversity of corporate forms is low } \\
\text { (very few cooperative businesses, } \\
\text { benefit corporations, or social } \\
\text { enterprises). }\end{array}$ & $\begin{array}{l}\text { Some grow heritage grain only as } \\
\text { rotational crop every } 3-4 \text { years to } \\
\text { augment growing alfalfa for the } \\
\text { meat and dairy industry-with } \\
\text { negative impacts. } \\
\text { Conventional road transport and } \\
\text { logistical challenges (relatively } \\
\text { small volumes) create } \\
\text { inefficiencies and associated GHG } \\
\text { emissions. } \\
\text { Small-scale harvesting, cleaning, } \\
\text { milling, malting, baking, and } \\
\text { brewing operations are less energy } \\
\text { efficient than large-scale } \\
\text { centralized ones. } \\
\text { Only a minority of businesses use } \\
\text { solar energy or energy-efficient } \\
\text { operations. }\end{array}$ & $\begin{array}{l}\text { There is less concern for } \\
\text { supporting farm workers and other } \\
\text { assisting jobs in the grain economy } \\
\text { to ensure living wages and } \\
\text { benefits. } \\
\text { The racial, ethnic and gender } \\
\text { diversity of people involved in the } \\
\text { local grain economy is limited. } \\
\text { Employee ownership is low. }\end{array}$ \\
\hline
\end{tabular}


the local grain economy by a narrow comparison against the conventional grain economy, which is focused on livestock feed, oriented toward exports, and driven by profit maximization. By contrast, the local grain economy focuses on food products for human consumption, generates value in the region, and balances economic viability with environmental and social benefits. A meaningful reference is therefore not the conventional grain economy, but the local economy. With focus on economic indicators, when consumers and businesses shift spending to businesses that are locally owned and operated, it increases the multiplier effect, keeping money circulating locally for longer, increasing output, jobs, and income, and expanding the total value of the local economy (Benedek, Fertő, \& Szente, 2020). This is what the local grain economy in Arizona has been demonstrating over the past several years. It might be of interest to economic development organizations, in particular as they consider the wider scope of sustainability, that businesses in the local grain economy have a significant local economic impact in addition to their social and environmental benefits.

Growth. On the surface, local grain businesses' desire for growth seems to follow the dominant neoliberal economic growth paradigm. Yet, the shared objective also seems to be the growth of the local grain economy (the economic network) in Arizona rather than the individual businesses. The vision is not for any individual business to outcompete the others and dominate the local market; instead, it is about adding more nodes and links to increase the overall impact. And there is a lot of potential for the local grain economy in Arizona to grow: for example, a fourfold growth in local grain production would only result in meeting $3 \%$ of flour consumption in the state, or a fourfold growth in local malting production would still only supply around 10 of the over 100 craft breweries. While there is considerable diversity in perspectives among the businesses engaged in the local grain economy, the common departure from the conventional growth paradigm aligns with the collaborative and cooperative nature of alternative food networks (Renting et al., 2003).
Supply-Chain Transparency. As the local grain economy in Arizona developed and became more differentiated in its operations, the network has added nodes and links. The result is that grain supply chains may not be so "short," taking up to four links (farm $\rightarrow$ handler $\rightarrow$ mill $\rightarrow$ bakery $\rightarrow$ consumer), or five if restaurants or retailers are inserted as the consumer point. This is stretching one of the key tenets of alternative food networks: the direct connection between producer and consumer, although the strength and validity of such connections has been called into question (Mount, 2012). It is observable in the marketing and sales of local grain products that the further up the chain the supply-chain actors are, the less visible and known they are to consumers. While the bakeries and breweries are well known (maybe even for using local grain), the processors might be somewhat known, but the farmers are often invisible. Additional marketing efforts in the local grain economy with support from local food advocacy groups (such as Local First Arizona) could help address this issue to avoid falling back into one of the key challenges of conventional food chains, namely, that people do not know where their food comes from.

Consolidation. In the initial few years of supplychain development in the local grain economy in Arizona, the growers were diverse: they included micro community organizations, small ecovillage farms and independent growers, and a couple of larger established farms looking to transition from conventional grain production. As the network evolved, there has been some consolidation toward a smaller number of the larger, conventional farms. In order to develop stability and reliable supply, contracts from mills to grain handlers to farms have been growing in volume and value. This is a consequence of financial investments and establishment of privately owned grain hubs that need a reliable network of growers to maintain quality and quantity standards. There is some concern that there are not enough farms and that this is a vulnerability for downstream businesses should, for example, one of the farms drop out suddenly. There is also the possibility of unhealthy concentration, which would counter the overall alternative 
food network's objective to support a variety of local farms.

Out-of-State Sales. An estimated 20\% of local intermediate products (flour, cleaned grains) produced in Arizona are sold out of state. There is no indication that processors particularly want to grow the export market, and the overall sentiment within the network is to keep it local. However, there is national demand for the high quality and unique products the Arizona processors are producing, and in the absence of stronger local demand, it seems a necessary part of their business. Out-ofstate sales, particularly online retail, were a significant factor in developing the Phoenix milling business when it struggled to reach viable volumes in the first few years. Similarly, both grain handlers have pursued sales to out-of-state artisan mills and bakeries and microbreweries to support their bottom line. In reality, businesses participating in alternative food networks often operate as hybrids, partly within and partly outside the network (Mount, 2012). However, out-of-state sales become a problem when they are pursued at the expense of in-state sales, resulting in local product scarcity and price increases, as well as exporting embodied water (in particular in naturally water-scarce environments such as Arizona). It can also be argued that when products are nationally available in larger volumes, they lose their local appeal in the place of origin: they are no longer perceived as special.

There are additional challenges for the local grain economy in Arizona to maintain resilience, high quality, local identity, and other beneficial features of a functional alternative food network. There is the issue of standardization. As the artisan bakers in Arizona learn how to work with White Sonora and other flours and collaborate with the local mills, there is a move toward the standardization of products, e.g., there are now standard bread flour mixes, blending various grains. Could this trend mean slipping back toward a centralized milling industry with three standard types of flour? There is also the issue of aggregation. While one mill in Arizona is a vertically integrated farming-handling-milling operation, the other receives grain from multiple growers and the original farm iden- tity is not always preserved. Currently, the malting has only one source but plans to add more once the processing capacity can accept it. With expansion to meet higher demand, there will be pressure to make processing as efficient as possible, which might jeopardize the preservation of source identity. And finally, there is the issue of corporatization. The idea that large corporations will need to be involved to significantly scale up the network was suggested by some supply-chain actors, as it has also been for alternative food networks in general (Clark \& Inwood, 2016; Stevenson \& Pirog, 2008). This already exists in the local grain economy in Arizona to some extent, with one mill's products being carried by the regional stores of several national retail chains.

In summary, the above are all well-known challenges that emerge alongside the growth and success of local food economies and alternative food networks (Mount, 2012). Consumer education, training, supportive local policies, investment and infrastructure development, and collaboration and cooperation can go some way to ensure the beneficial features of an alternative food network are maintained (Diamond \& Barham, 2011; Lutz \& Schachinger, 2013), many of which were also mentioned by participants in this study. Yet, hybridity might be necessary for building an alternative food network (Mount, 2012; Tregear, 2011), and some strategies might deviate from the purist vision of a sustainable local grain economy (Lutz \& Schachinger, 2013; Nost, 2014). Examples from the local grain economy in Arizona include transporting grain out of state and back to have it malted, or blending Arizonan White Sonora with imported flours to achieve a functional mix, or brewing a beer with only minor local grain content. It would be important, however, to ensure that the core values and goals are maintained and even strengthened.

As noted in the Research Methods section, there are limitations to the study. Data completeness was further curtailed when the COVID-19 pandemic began a couple of months into the data collection process. Mills and bakeries became extraordinarily busy, and breweries scrambled to adapt, resulting in very limited time to respond to requests for further information. A more general 
point is that government at any level does not collect the data needed to monitor and analyze alternative food networks. As experienced by ourselves and others (King, Hand \& Gomez, 2015; Thompson, Harper \& Kraus, 2008), economic datasets, such as those collected by federal and state agencies, do not include data with the granularity, specificity, and completeness that is needed to track the activities and throughput of local supply chains. Data collected by federal and state agricultural agencies, for example, on in-state vs. out-of-state crop sales, and to which sector (e.g., animal feed, milling, malting), would allow a high-level picture of upstream production in a local grain economy. Yet, such general data would still not suffice for indepth supply-chain studies. More promising would be a self-governed, collaborative effort centered on primary processors, with participation by producers and downstream processors and retailers, to establish a specific data collection and reporting program for the local grain economy.

\section{Conclusions}

This study offers an account of Arizona's local grain economy - its size, structure, and evolution - and an initial assessment of its sustainability. Over the past decade, this economy has formed a functional alternative food network; in some sectors it is already stable, while in others it is still quite dynamic (with new and existing businesses). Sustainability has been a driving factor from the beginning, with good achievements and still a great deal of potential for improvement. It seems the network is reaching another critical stage, in which issues of growth, consolidation, transparency, standardization, aggregation, and corporatization will require deliberate strategies to maintain sustainability.

The profile we constructed of the local grain economy in Arizona can serve as a basis for further development. It raises questions for future partici- patory research, including what were the success factors at each stage of the economy's evolution, what is the vision for the next decade, what are strategies to navigate the issues currently faced and move toward such a vision, as well as detailed research on aspects of its current state, such as a more robust determination of local economic multipliers and a more comprehensive sustainability appraisal. The study also provides a focus to convene the local grain economy stakeholders in Arizona to reflect on values, goals, challenges, and directions, and to develop coherent and collaborative development efforts. Continuous monitoring and evaluation, as outlined here, would provide evidence-based data for policy advocacy and fundraising.

Beyond its immediate value to the local grain economy in Arizona, the approach used in this study could be of value to other regions to conduct similar analyses of local grain economies. The various data collection and analyses on production quantities, supply-chain networks, network development, local economic impact, and sustainability offer a pragmatic framework to improve understanding of the current state and identify future possibilities. It may also, by extension, be applied to other types of alternative food networks. Perhaps of most value, however, is that application of the framework by researchers in other regions would allow for cross-case comparisons that could yield robust insights into local grain economies in general.

\section{Acknowledgments}

The authors would like to thank the many businesses and individuals whose generosity of time and information made this work possible. The authors would also like to thank the anonymous reviewers for valuable feedback on earlier versions of this manuscript.

\section{References}

Allen, L. (2019, November 6). Forecasts mixed for Arizona wheat production. Farm Progress. https:// farmprogress.com/wheat/forecasts-mixed-arizona-wheat-production

Allen, P. (2010). Realizing justice in local food systems. Cambridge Journal of Regions, Economy and Society, 3(2), $295-308$. https://doi.org/10.1093/cjres/rsq015 
Bastian, M., Heymann, S., \& Jacomy, M. (2009). Gephi: An open source software for exploring and manipulating networks. Third International AAAI Conference on Weblogs and Social Media. https://gephi.org/publications/gephi-bastian-feb09.pdf

Benedek, Z., Fertő, I., \& Szente, V. (2020). The multiplier effects of food relocalization: A systematic review. Sustainability, 12(9), 3524. https://doi.org/10.3390/su12093524

Carlisle, L. (2019, November 13). Flour Power. YES! Magazine. https://www.yesmagazine.org/issue/building-bridges/2019/11/13/flour-power/

Clark, J. K., \& Inwood, S. M. (2016). Scaling-up regional fruit and vegetable distribution: Potential for adaptive change in the food system. Agriculture and Human Values, 33(3), 503-519. https://doi.org/10.1007/s10460-015-9618-7

Deller, S. C., Lamie, D., \& Stickel, M. (2017). Local foods systems and community economic development. Community Development, 48(5), 612-638. https://doi.org/10.1080/15575330.2017.1373136

Diamond, A., \& Barham, J. (2011). Money and mission: Moving food with value and values. Journal of Agriculture, Food Systems, and Community Development, 101-117. https://doi.org/10.5304/jafscd.2011.014.013

Duval, D., Kerna, A., Frisvold, G., \& Avery, C. (2016). The contribution of small grains production to Arizona's economy. Department of Agricultural and Resource Economics Cooperative Extension, The University of Arizona. https://agriculture.az.gov/sites/default/files/documents/The $\% 20$ Contribution $\% 20$ of $\% 20$ Small $\% 20$ Grains $\% 20$ Pro duction $\% 20$ to $\% 20$ Arizona $\% 27 \mathrm{~s} \% 20$ Economy.pdf

Feenstra, G. W. (1997). Local food systems and sustainable communities. American Journal of Alternative Agriculture, 12(1), 28-36. https://doi.org/10.1017/S0889189300007165

Galli, F., Bartolini, F., Brunori, G., Colombo, L., Gava, O., Grando, S., \& Marescotti, A. (2015). Sustainability assessment of food supply chains: An application to local and global bread in Italy. Agricultural and Food Economics, 3(1). https://doi.org/10.1186/s40100-015-0039-0

Halloran, A. (2015). The New Bread Basket: How the New Crop of Grain Growers, Plant Breeders, Millers, Maltsters, Bakers, Brewers, and Local Food Activists Are Redefining Our Daily Loaf (1st edition). Chelsea Green Publishing.

Hergesheimer, C., \& Wittman, H. (2012). Weaving chains of grain: Alternative grain networks and social value in British Columbia. Food, Culture \& Society, 15(3), 375-393. https://doi.org/10.2752/175174412X13276629245803

Hills, K. M., Corbin, A., \& Jones, S. S. (2011). Rebuilding the grain chain: Stories from the coastal Pacific Northwest. Rural Connections, 6(1), 31-36. https://www.usu.edu/wrdc/files/news-publications/RC-Sept-2011.pdf

Hills, K. M., Goldberger, J. R., \& Jones, S. S. (2013a). Commercial bakers and the relocalization of wheat in western Washington State. Agriculture and Human Values, 30(3), 365-378. https://doi.org/10.1007/s10460-012-9403-9

Hills, K. M., Goldberger, J. R., \& Jones, S. S. (2013b). Commercial bakers' view on the meaning of "local" wheat and flour in Western Washington State. Journal of Agriculture, Food Systems, and Community Development, 3(4), $13-32$. https://doi.org/10.5304/jafscd.2013.033.022

Jones, E., \& Harvey, D. (2017). Ethical brews: New England, networked ecologies, and a new craft beer movement. In Nate Chapman, J. S. Lellock, \& D. Lippard (Eds.), Untapped: exploring the cultural dimensions of craft beer in the US. West Virginia University Press. http://www.academia.edu/download/51884872/2017-Jones and Harvey Ethical Brews.pdf

King, R. P., Hand, M. S., \& Gomez, M. I. (Eds.). (2015). Growing local: Case studies on local food supply chains. University of Nebraska Press. https://doi.org/10.2307/j.ctt1d9nk8d

King, R. P., \& Venturini, L. (2005). Demand for quality drives changes in food supply chains. USD A Agricultural Information Bulletin, 794, 18-31. https://www.ers.usda.gov/webdocs/publications/42581/30120 aib794d 002.pdf?v $=5599.2$

Lutz, J., \& Schachinger, J. (2013). Do local food networks foster socio-ecological transitions towards food sovereignty? Learning from real place experiences. Sustainability, 5(11), 4778-4796. https://doi.org/10.3390/su5114778

Mann, E. (2016). Diverse forms of market engagement: Grounding food sovereignty in the experiences of Ontario's ecological grain farmers. Master's thesis, University of Waterloo. Retrieved from https://uwspace.uwaterloo.ca/handle/10012/10876 
Milestad, R., Bartel-Kratochvil, R., Leitner, H., \& Axmann, P. (2010). Being close: The quality of social relationships in a local organic cereal and bread network in Lower Austria. Journal of Rural Studies, 26(3), 228-240. https://doi.org/10.1016/i.jrurstud.2010.01.004

Mount, P. (2012). Growing local food: Scale and local food systems governance. Agriculture \& Human V alues, 29(1), 107121. https://doi.org/10.1007/s10460-011-9331-0

Nabhan, G. P. (2018). Immigrant grains. In G. P. Nabhan, Food from the radical center (pp. 109-121). Island Press/Center for Resource Economics. https://doi.org/10.5822/978-1-61091-920-3 11

Nost, E. (2014). Scaling-up local foods: Commodity practice in community supported agriculture (CSA). Journal of Rural Studies, 34(Supplement C), 152-160. https://doi.org/10.1016/j.jrurstud.2014.01.001

Renting, H., Marsden, T. K., \& Banks, J. (2003). Understanding alternative food networks: Exploring the role of short food supply chains in rural development. Environment and Planning A: Economy and Space, 35(3), 393-411. https://doi.org/10.1068/a3510

Robinson, Z. (2020, April 25). Real Bread Bakers [Documentary]. https://gumroad.com/1/psrqH

Sen, I. (2008, September 9). Flour that has the flavor of home. The New York Times. Retrieved from https://www.nytimes.com/2008/09/10/dining/10wheat.html

Smith, J., \& Barling, D. (2014). Glamur project UK wheat to bread supply chain case study. City University London.

Steavenson, W. (2019, October 10). Flour power: Meet the bread heads baking a better loaf. The Guardian. Retrieved from https://www.theguardian.com/food/2019/oct/10/flour-power-meet-the-bread-heads-baking-a-better-loaf

Stevenson, G. W., \& Pirog, R. (2008). Values-based supply chains: Strategies for agrifood enterprises of the middle. In T. A. Lyson, G. W. Stevenson, \& R. Welsh (Eds.), Food and the mid-level farm (pp. 119-144). The MIT Press. https://doi.org/10.7551/mitpress/9780262122993.003.0007

Thomas, D. (2013). Malting: The latest craft. Brewer \& Distiller International, 47-49. https://www.blacklandsmalt.com/press/Brewer \& Distiller International 0713.pdf

Thompson, Jr., E., Harper, A. M., \& Kraus, S. (2008). Think globally_Eat locally: San Francisco foodshed assessment. American Farmland Trust. https:// farmlandinfo.org/publications/think-globally-eat-locally-san-francisco-foodshed-assessment/

Tregear, A. (2011). Progressing knowledge in alternative and local food networks: Critical reflections and a research agenda. Journal of Rural Studies, 27(4), 419-430. https://doi.org/10.1016/i.jrurstud.2011.06.003

U.S. Department of Agriculture, National Agriculture Statistics Service [USDA NASS]. (2019). Small grains annual summary. USDA Economics, Statistics and Market Information System. https://usda.library.cornell.edu/concern/publications/5t34sj573?locale $=$ en

Wu, T. (2020, July 24). That flour you bought could be the future of the U.S. economy [Opinion]. The New York Times. https://www.nytimes.com/2020/07/24/opinion/us-grain-industry.html

Yin, R. K. (2003). Case study research: Design and methods (3rd ed.). SAGE. 